\title{
IMPEDIMENTS TO ENHANCING RESEARCH WITHIN Universities in Developing Context: The Case of PAKISTANi Universities
}

\author{
Marodsilton Muborakshoeva ${ }^{a}$ \\ Institute of Ismaili Studies, London
}

\begin{abstract}
Universities in some developing countries are undergoing reforms over the recent decades so that they become research-based institutions. It has been stressed that research is of paramount importance for enhancing the economy of a country and for societies to become knowledge-based. However some of these concepts and challenges faced by these universities are hardly explored. Relying on the analysis of qualitative interviews and document analysis, this paper examines how the Higher Education Commission (HEC) has taken numerous initiatives to boost the research capacity of universities in Pakistan. Even then, numerous challenge remains in the attempt to enhance research quality. Funding and its effective use, academic freedom, and value of research in the society emerged as major impediments to research development at the universities. Critical voices from the university faculty are rarely taken into account by those responsible for higher education bodies, therefore many of such challenges persist till date. The article proposes solutions for overcoming some of these challenges and situates the experience of Pakistani universities within the broader experiences of universities world-wide.
\end{abstract}

KEYWORDS: higher education, Pakistani universities, research, academic freedom, value of research

\section{Introduction}

The importance of research and the urge for universities of the developing contexts to become research-based institutions has grown into a pressing matter over recent decades. It is suggested that research, along with many other functions of universities, is of paramount importance for enhancing economy of a country and for societies to become knowledge-based (UNESCO, 1998; World Bank, 2000, 2002; Salmi, 2009; Altbach, 2007, 2013). Universities should increase their research output and enhance its quality, since the latter is a prerequisite for a knowledge-based society (Tilak, 2002). In response to the prompt, many developing countries rehabilitated their higher education by boosting expenditure on research and creating structures such as Multimedia Super Corridor (MSC) in Malaysia, and Cyberservice Corridor (PCC) in the Philippines, both moving towards embracing a knowledge-based economy (Symaco, 2012). Other countries, like Pakistan, are similarly eager to reform their universities and make them research-based with the vision of enhancing its economy and transforming its society into one based on knowledge (Government of Pakistan, 2002; Higher Education Commission, 2012, 2013).

Based on the analysis of qualitative interviews and document analysis, this paper explores how the Higher Education Commission (HEC), an influential regulating and funding body for universities in Pakistan, has taken numerous initiatives to boost the research capacity of universities. Yet, amidst

Correspondence can be directed to: mmuborakshoeva@iis.ac.uk 
the reform, dissenting voices of university faculty and their concerns about the major impediments to enhancing research quality at the universities are rarely taken into account, either by HEC or the government. Moreover, in Pakistan, similar to other developing contexts, those concerned with research development at the universities and a wider population of intellectuals scarcely have the freedom for open and critical discussions about major challenges universities face or the conceptual issues in higher education. Rarely has qualitative research been done at the grass-root level to get the thoughts of university faculty on the challenges universities face, or on what the relationship between the various challenges is. This paper aims to fill these gaps and hope that when enhancing research quality at the universities, HEC will pay heed to these criticisms and include relevant university faculty in the decision making process while trying to resolve some of these challenges. Funding and its effective use, academic freedom and the value of research in society emerged as the key impediments to research development at the universities in Pakistan in this study.

We will start with a review of relevant literature and examine some key definitions. Then, a brief overview of the state of research in Pakistani universities will be given and reform initiatives by HEC in relation to research development at universities will be discussed. Afterwards, major impediments to enhancing research at Pakistani universities are explored. Finally, recommendations for overcoming some of these challenges are proposed and the experience of Pakistani universities is located within the broader experiences of universities world-wide.

\section{Research at the Universities and Key Definitions}

There is a dearth of literature on universities' research quality in general, and even more so on research at the universities in Pakistan. Higher education research is rightly recognised as an underdeveloped field (Altbach et. al., 2006), but in the context of a developing country such as Pakistan, the situation of the field is bleaker still. For example, out of the 244 universities in Asia engaged in higher education research from 1980 to 2012, 66 percent have published one article and 15 percent published two articles in research journals (Jung and Horta, 2013). Only four universities from Pakistan are engaged in such research publication and are not listed among the top ten countries with the higher percentage of publication, but fall within the institutions with a low level of engagement in higher education research (Ibid). As a result there is little research available on how universities in Pakistan conduct research, in which areas, what they have achieved so far and what needs to be improved. Neither are there discussions on what is meant by the words 'worldclass universities', 'research universities', nor 'knowledge-based society or economy'. Therefore we need to first clarify what we mean by these definitions.

Kapur and Crowley (2008) highlighting the importance of higher education for developing countries as well as broadening research agenda of the universities, caution us about using 'knowledge economy' and 'knowledge-based society' uncritically. Some assert that knowledge economy is "different from traditional industrial economy because knowledge is different from traditional commodities and therefore, requires different organisation and modes of distribution." It has many characteristics "of a global public good and is not bound by the law of scarcity that affects other commodities" (Stiglitz, 1999 in Kapur and Crowley 2008, p.14). Others disagree and state that knowledge economy does not mean a new mode of production, rather there is a new type of relationship between knowledge production and economy. Bastalich (2010, p.845) argues that despite the claims of policy makers, "knowledge economy' 'does not describe a "new" mode of economic production, but a discursive recasting of the relations between ideas and production'. The policy environments underestimate the value and role of universities within a democracy and fall short of recognising and supporting the unique nature of university knowledge production and innovations (Ibid.). In any case, all these various views have one thing in common, namely that knowledge economy does require a new type of organisation of knowledge production and its distribution.

Despite the excitements about 'knowledge economy' in the developing countries very little is known about whether it works, and how. This is perhaps mostly due to the vague relationships 
between the goals of higher education and individual benefits (Kapur and Crowley, 2008). Added to this is the lack of statistical data on higher education in the developing countries (Ibid).

'Research universities' are defined as "academic institutions committed to the creation and disseminations of knowledge in a range of disciplines and fields, featuring the appropriate laboratories, libraries and other infrastructures that permit teaching and research at the highest possible level" (Altbach, 2007, p.1). It is argued that countries should develop their research universities, linking them with the global scientific network so that they may participate in them and benefit from the scientific advancements (Altbach, 2007). World-class universities have highly sought-after graduates, leading-edge research, and technological transfer that are a direct result of a strong faculty and student body, abundant resources and effective governance (Salmi, 2009).

Most universities in the developing countries, including Pakistan, are lacking these main characteristics of a research university and/or world-class universities. That is why we avoid using these definitions in relation to Pakistani universities and focus on 'enhancing research at Pakistani universities' instead. Universities globally are facing numerous challenges such as (lack of) funding, untenable research culture, autonomy and accountability, market oriented research, academic freedom (Altbach, 2007), yet these challenges are faced more strongly in the developing countries. Case studies of some universities in Pakistan demonstrate that there are some context specific challenges. The most outstanding ones are funding, academic freedom, quality assurance, leadership and management, organisation of knowledge, enhancing research culture at the universities, reconciliation of modernity with tradition, and teaching of Muslim cultures and civilisations, especially religion (Muborakshoeva, 2013). These challenges need to be examined in detail when thinking about developing research at universities in Pakistan generally and transforming them into research-based, or world class universities particularly.

\section{Methodology}

Documentary (both primary and secondary) sources as well as interviews with prominent academics at seven higher educational institutions in Pakistan have been collected and analysed in this article. The overall design is grounded theory, which is often used in studies where there is a lack of theoretical knowledge in the field (Glazer and Strauss, 1967). As Ashwin (2012) argues, it is very rare that research findings develop explicit theories despite research in higher education having enormous value in contributing to the development of higher education practices. The empirical data collected and analysed in this article, therefore is part of a larger study conducted on the overall aims and concepts of higher education in Muslim contexts, the bulk of the findings for which were published as a book (see Muborakshoeva, 2013). The book highlights that higher education in Muslim contexts, rich in heritage and conceptually diverse, faces many challenges in contemporary times. Due to the nature of the book, there is little opportunity to discuss some of the challenges universities face at a deeper level. In this article, I am focusing on the analysis of data on research culture at Pakistani universities and what challenges they face in conducting research.

For the purpose of this paper I will use the qualitative interviews conducted with 18 scholars at seven higher educational institutions - the University of the Punjab, Karachi University, the Aga Khan University, Hamdard University, Lahore University of Management Sciences, University of Management and Technology, and National College of Arts. The decisive factor in sample selection was their well-recognised research, extensive experience of working in different universities in Pakistan and abroad, and being aware of the wider issues and challenges universities face in relation to research rather than being representative of the university or certain institution within that university (for the profile of the interviewees see Muborakshoeva, 2013). In this article I quote the interviewees by their role or position at the university.

The strengths and weaknesses of the research design and qualitative interviews were evaluated and possible biases were eliminated. For example, notions such as going to the field with 'a blank mind' and not having prior preconceptions (Glazer and Strauss, 1967), were critically examined. In 
terms of reliability of the tools used for data collection and validity of the data gathered and analysed, attempts were made to eliminate personal biases, make accurate analysis and judgements, and check the plausibility of the claims in light of existing knowledge as well as using triangulation techniques. To verify claims made by the respondents, the researcher relied on wider literature and analysis of interview transcripts, observation notes and documents.

Although this study did not come up with more general theories, it nevertheless succeeded in generating substantial understanding of the issues that speak for the populations they were derived from. The issues and challenges that emerged included funding and its effective use, academic freedom, and value of research in society. The study considers these to be the major obstacles to developing research at the universities in Pakistan. It is therefore hoped that the findings of this study have 'the language of explanatory power' (Strauss and Corbin, 1998) with regard to numerous universities in Pakistan and other developing countries with similar background, history and structural organisation.

\section{Findings}

\section{The State of Research at Universities of Pakistan}

Since the inception of the earliest universities in the areas that became Pakistan, there had been debates as to whether the universities should be research or teaching institutions. For instance, when establishing University of the Punjab in 1880s, the orientalist scholars and local intellectuals of the Punjab insisted that the university should promote knowledge creation and its dissemination in vernaculars. The British officials and colonialist, on the other hand, wanted it to be a teaching university with English as a medium of instruction and prepare civil servants and educated work force for colonial industries (Mathur, 1968, Singh, 1993, Muborakshoeva, 2013). The orientalists and local intellectuals seemed to win the debate, however, in the decades to come it gradually became more of a teaching university. A lecturer from University of the Punjab told me that 'at the inception, its aim was to promote knowledge and create an academic atmosphere to conduct research and organise seminars and conferences, but with the passage of time, it was converted to a routine institution'. The reason as to why this change happened at the Punjab University is probably connected with the overall social and political developments in the subcontinent, its division into two countries, and priorities set by the national states. Since the 1950s, with the establishment of Karachi University and other universities in 1960s and 1970s, it was clear that the emphasis was more on teaching, preparing civil servants and highly educated people to meet the needs of the newly established state of Pakistan (Akhtar, 1977, Muborakshoeva, 2013). Nevertheless, research has always been part of the mission and vision of these universities. Research of a high calibre was produced by these early Universities of Punjab, Karachi, Sindh, and others. Prominent scholars and researchers had been working at these universities and two graduates of the Punjab University received Noble Prizes later on (Muborakshoeva, 2013).

However, scholars I have interviewed expressed their dissatisfaction with the state of research at the universities of Pakistan since the last few decades of the past century. They thought that it is of a low quality and regretted that none of their universities are at the top list of world university ranking. The interviewees highlighted that 'the culture of research' at Pakistani universities and research conducted at some public universities was more in the line of being 'conformist' and 'routine', with a lack of rigorous 'critical approaches'.

With regard to challenges in research, the interviewees highlighted that funding and its effective use, academic freedom, the value of research in society, quality assurance, marketing research findings, and lack of adequate policies and procedures stands in the way of research dissemination (Muborakshoeva, 2013). We shall discuss in this paper how some of these challenges were addressed yet, some persist and need to be addressed by the government, the HEC, university management, and the society as a whole. 
This 'lack of research culture' and the weak research quality at the universities pushed the intellectuals and government agencies to revise the existing policies and give more freedom to higher educational institutions to enhance their research quality. This flexibility allowed private universities to be established in Pakistan since the 1980s. The Aga Khan University, Lahore University of Management Sciences, Hamdard University, and many others are cases in point which have embraced a strong research agenda in their mission statements. Studies conducted at these universities are of high quality and internationally recognised; they are great examples for public universities in enhancing research. However, the most prominent boost to research development at Pakistani universities comes from the Higher Education Commission (HEC).

\section{Enhancing Research at Universities by Higher Education Commission (HEC)}

HEC has initiated a series of reforms at higher education institutions in Pakistan since the beginning of this millennium. Being set up by the government of Pakistan in 2002 as a replacement for the then office of University Grants Commission, HEC was granted more power and freedom in terms of higher education's regulation, management and co-ordination. The large-scale reforms by HEC since its inception paid off and it achieved considerable success in developing faculty, quality assurance, access to higher education, equipping universities with updated IT and technology, and staff remuneration. Particularly significant are the efforts of HEC in enhancing the quality of teaching and learning, but it is only concentrated on research relevant to economy and industries of the country. This success was notable since the beginning of HEC's establishment, especially under its then chairman, Dr. Ata ur-Rahman's leadership, where funding from foreign and domestic sources and donors were successfully obtained. However, from the year 2008, the funding for universities through HEC has fallen drastically, particularly so for the years after 2010 (a point we shall discuss later on). Nevertheless, HEC is still committed to improving the quality of research at universities across Pakistan. This quote from the chairperson of HEC, Mukhtar Ahmed, gives the scale of research capacity development among Pakistani scholars:

' (...)over 6000 scholars have been sent abroad/financed under various HRD programmes for MS, PhD, Post-doctoral research and under the International Research Support Initiative Programme. Out of these, around 4000 have successfully completed their studies and returned to serve in Pakistan. While more than 5000 scholarships have been awarded under indigenous schemes of which around 1200 scholars have completed their doctoral degrees. In addition, the first batch of 1000 scholars has been provisionally selected during 2012-13 under Phase-II of the Indigenous PhD Fellowships' (Higher Education Commission 2013, p.ii)

The Research and Development division at HEC provides support for universities and academics 'in four major areas such as (a) promotion of research in universities, (b) capacity building of researchers and faculty, (c) support to universities in promoting research, and (d) commercialization of research' (Ibid).

To promote research at universities, the National Research Program for Universities (NRPU) gives research grants to university teachers for scientific research. Out of 674 research proposals in 2012-13, 94 have been approved for funding, 141 have been rejected so far and 566 are under the evaluation process. Other initiatives are the Pakistan-US Science and Technology Cooperation Programme, HEC-British Council strategic partnership in Research and Education, International links of Pakistani universities with foreign universities (Ibid.). Pakistani universities also attempt to obtain an Associate Membership of CERN, the European Organisation for Nuclear Research (Higher Education Commission, 2014).

To build the capacity of researchers and faculty, travel grants are given to researchers to present their research findings at national and international conferences. The Textbook and Monograph Writing scheme aids the faculty, researchers, and scholars with the publication of 
their work. Opportunities are offered for collaborative research and dissemination of research findings through the organisation of seminars and conferences. Universities can borrow scientific instruments from each other, where HEC reimburses the cost, and apply for grants for purchase of laboratory equipment. Pakistani universities have access to numerous electronic research journals of 478 institutions, for which HEC spends more than Rs. 900 million ( 8.9 million USD) per annum on subscription of e-resources. Research publications by universities and degree awarding institutions are rated by HEC for quality using international benchmark and criteria (Higher Education Commission, 2013).

Structures are put in place to link research at universities with economy and businesses. For instance, the Business Incubator Centres (BIC) assist researchers and young entrepreneurs who intend to develop promising business ventures. So far eight BICs have been established in eight universities. The Office of Research and Innovation and Commercialisation (ORIC) provides strategic and operational support to research activities in higher education institutions, of which 27 (i.e. ORICS) have been established at public and private universities and their performance rigorously monitored (Higher Education Commission, 2013).

Measures are put in place by HEC to make sure that the PhD holders serve Pakistani society for at least 5 years. This is in response to increased concerns about the rationale behind HEC's providing scholarship for postgraduate studies abroad and in Pakistan who leave the country after obtaining their degree. The concerns some interviewees in this study shared were that those scholars who do not contribute to Pakistani society ultimately benefit only personally and do not contribute to the public good in Pakistan.

Consequently, through these initiatives for enhancing research at both public and private universities, it can be argued that HEC enabled universities to overcome some of these challenges. Funding research via various schemes improved, quality of research was enhanced and support mechanisms for collaborative research, dissemination of research output, and commercialisation of research were created. Even though there is a huge gap between research output in Pakistan and India, and it is parked behind Iran and Malaysia in this regard (SJR, 2015), the quality of research is steadily expanding in Pakistan and its scientific indicators are encouraging. HEC, therefore, has been able to promote research culture at the universities and encourage them to use opportunities provided for the purpose of research enhancement. However, there are some persistent challenges to research development at the universities highlighted by intellectuals and university faculty; dissenting voices that are hardly being acknowledged by the government or HEC.

\section{Key Impediments to Enhancing Research at Universities}

Despite the success stories discussed earlier, there are many areas for improvement, some highlighted by HEC and others pointed out by critics. Scholars I interviewed in Pakistan brought to the attention additional and more pressing unresolved issues related to enhancing research quality at universities. These are concerns over funding and its effective use, academic freedom, and the value of research in society.

\section{Funding and its Effective Use}

Funding, which has been an on-going issue for higher education in Pakistan (see Isani and Virk, 2005) could be resolved by the persistence of HEC in demanding for increase in funding for higher education from the government, and by co-operating with international funding bodies. A lecturer stated that due to strong leadership skills of Ata ur-Rahman at HEC a lot of international aid money that came to Pakistan was channelled towards university and research purposes, which increased the research output in science. However, he thought, as it often happens in the developing countries, sometimes this funding was not utilised efficiently and could have fallen into the hands of a corrupt leader or an ineffective manager of a university. This relative generosity did not last long and with 
the change of government in Pakistan, funds for higher education have drastically fallen again since 2010. This is a major challenge which HEC is struggling to resolve with the government. Others also claim that even when funds were in abundance, especially from 2000 s to 2006 , they were not utilised effectively and were spent inefficiently on unnecessary expansions, tenured professors' salaries and unrealistic partnership with foreign universities (Hoodbhoy, 2010). In defence, the former chairman of HEC Jawaid Laghari (2010) emphasised that HEC was learning from its past experiences and had aligned its focus on managing finances efficiently, attaining equitability in growth, placing emphasis on quality, and furthering relevance in research. However, over the recent years, things are moving slowly and potential candidates for scholarships complain (Higher Education Commission, 2011a) about tardy response from HEC about the state of their applications. Furthermore, those on HEC scholarships abroad complain about delays in their tuition payments. The very fact that out of 674 research proposals for 2013-14 a high number of them (566) was still under review in 2014 demonstrates a slow pace of work by HEC which translates into a long wait for university faculty. Perhaps the lengthy process of selecting and appointing the chairman of HEC in 2014 also contributed to such deficiencies.

The lack of appropriate funding, ineffective use of funding, and delays in providing funds results in poor research output discourage potential postgraduate candidates and university faculty in conducting research. The situation is worsened by the fact that out of the small pool of students enrolled at university, the more gifted ones opt for sciences, business studies, and Information Technology (IT). A vice chancellor emphasised that one cannot expect high quality research from underfunded universities where barely 7 per cent of students get enrolled. Another lecturer added that humanities and social sciences 'end up recruiting weaker students, so there is little prospect to expect research of a high calibre from them'.

Most scholars agreed that research conducted in humanities and social sciences get less funding although it houses the vast majority of students who ended up opting for social sciences, arts and humanities, and religious education due to poor education and greater availability of seats (Muborakshoeva, 2013). Out of the total 481 research projects listed by the National Research Program for University only a few are on education and social sciences and none on humanities and arts. Moreover, the number of those approved (153 projects) is almost the same as those rejected (118 projects) (Higher Education Commission, 2011b, pp.55-57). This in turn, suggests that more funding should be allocated to resources and support structure for the university faculty to assist them in developing quality research proposals. It is, however, notable to observe the inclusiveness of HEC in funding quality research proposals from private universities. Scholars at private universities thought that since they manage funds very well and utilise it efficiently, "it was about time the HEC considered funding some private universities that manage resources well" (Muborakshoeva 2013, p.128). It seems HEC has taken this suggestion of the faculty from private universities on board.

If one looks at the allocation of funds for the fiscal year of 2013-14, higher education received a lion share ( 73 per cent out of the Rs 86.4 billion ( 856.4 million USD)) of the fund, and in principle should be better off than other educational sectors. However, taking inflation (of 8.7 per cent) into account this budget is in fact a decrease of 11 per cent and is equal to Rs 78.9 billion (782.1 million USD) in real term (Junaidi, 2014). Adequate funding therefore has a close correlation with quality research and is one of the most important factors in enhancing research quality at university level.

\section{Academic Freedom}

As far as academic freedom is concerned, most of the university faculty I have consulted thought that it has a close correlation with both funding and societal conditions. The more a university is independent financially, the more freedom it enjoys in conducting research. Such universities also successfully deal with the political and religious pressures. The National College of Arts, some schools at Karachi and Punjab universities, the Aga Khan University, Lahore University of Management Sciences, Hamdard University, University of Management and Technology are such examples 
(Muborakshoeva, 2013). Nevertheless universities, including those aforementioned, experience some degree of societal pressures albeit in various forms.

A Rector of a university likened academic freedom exercised at the universities to the overall freedom practised in Pakistani society; this view leaves little room for the vibrant development of universities:

\begin{abstract}
'Universities flourish in societies which are open and democratic. If the state is not democratic, you cannot expect much from the university. Universities cannot be islands of freedom of thought if the society is not supportive (...) universities are laboratories in that sense, they come up with suggestions, proposals and transfer that into society to implement. That type of relationship does not exist; societies are governed by [a] particular [group of] elite, a particular set of institutions which are not bothered about getting input from universities. I mean our bureaucracy and military, for instance, design foreign policy of the country without consulting what the professor of International Relation thinks or what research he has produced.'
\end{abstract}

He further elaborated that 'universities are think tanks that produce research for the benefit of the society and policy making, but that type of relationship does not exist between universities and society'. To him if the society 'is not functional and democratic, we cannot expect good universities there to produce knowledge and propose solutions to the issues of society'. Additionally, political and religious parties interfere in the affairs of the universities, which ultimately impede the proper functioning of universities, including conducting research freely at the institutions. A dean of an institute emphasised that although he was not against political parties having their students' wings at the campuses, he strongly condemned the unwarranted interferences of the government or political parties into everyday business of the institutions which serves to damage the image and confidence of the institutions and is a constant challenge for them. In his view,

'Political interference into the affairs of the universities should be eradicated. There are different types of political influences, first there is interference from the government asking a university to do this or that, in appointment of high officials of the university too the government has its influence (...) Secondly, there are political organizations, which also interfere in the matters of the universities (...) there is nothing wrong for a political organization to have its students' wing, but it should have certain norms of conduct and discipline. Political organizations should not interfere with the administration of the university in the sense that they ask for political favours from [the] university and the teaching staff, or they interfere with the judgment of the teachers as to whom to award good marks, to whom to give first position or second, who should be given admission and so on and so forth (...) This is a very big challenge.'

Students' political activism at Pakistani universities has a long history and although to eradicate it completely has been proven almost impossible, nevertheless the constant ban on students organising unions has worked and the level of violence carried out by various students' political and religious groups reduced significantly as compared with the 80s and early 90s (Paracha, 2014). Now intellectuals and academics are of two opinions, one in support of the ban on students' political activism, and others against the ban (Ibid). Similarly, the religious groups and parties have their own influences at the universities through their students' wing. The religious sway started with a simpler mission of influencing the students to make them 'better Muslims', but by mirroring other secular political parties, they too started using different methods, including violence and imposing their agenda on others (Paracha, 2014). 'Islamisation' at the universities, for instance, was one of such agenda, which was initiated by Zia ul-Haq (1976-87). Since then the teaching of Islamic Studies became compulsory at the universities, which in itself was not an unscrupulous initiative. However, the teaching of this subject was not as creative and free as the academics would have wanted it to be (Muborakshoeva, 2013). Moreover, the pressure exerted by religious and political parties at the 
societal level has an impact on academic freedom. Some religio-political parties are generally hostile to critical and creative research in Islamic studies and very defensive of religion and its dogmas. A scholar told me that challenging the belief system openly would not be tolerated by such groups even though their attitude towards some academic publications on religion would be somewhat relaxed:

'(...) of course if in a certain university anybody stands up and says anything about God or the Prophet, which goes against Islamic belief, he would be knocked out, he would not be tolerated... You can be lousy, careless about your faith, you can afford to pray or not to pray, even if you say that Islam is out of fashion you still survive, but challenging the belief system and questioning the basics would not be tolerated. Pluralism is there to an extent as it is in the society, this is how it is in the overall society as well. If I write an essay saying that the belief in God is not justified and rationalism is this and that and publish it in a newspaper may be, I would be excused as an intellectual, but if I stand and say it in a classroom I would face a very hostile crowd.'

A possible reason for the more rigid religious groups not challenging the scholars about their publication is that most of them are published in English and hence not accessible to the masses. However, seeing that Pakistan and its institutions have produced the most renowned scholars in all fields, including those in Islamic Studies (e.g. Fazlur Rahman), there could be other reasons for relatively tolerable approach to academic research and publication. Another academic believed that the religious groups' concerns about critical thinking damaging religion were groundless, since it was critical thinking in sciences, philosophy, religion, and humanities in the early centuries of Islam that made it a dynamic religion and a civilisation.

As we stated earlier, in most cases exercising academic freedom is correlated with the financial situation of an institution. There are many examples of universities in Pakistan where they enjoy academic freedom due to being more financially independent from the government. For instance, the National College of Arts (NCA), which has creative ways of raising funds, enjoys more academic freedom as compared with the Institute of Art and Design at the Punjab University. A lecturer explained the reason as to why this is the case:

'(...) there is much more academic freedom in NCA than in other institutions. NCA is the only public institution in the country which has earned a lot of distinction because of their academic freedom from the state influence, from the influence of the mullah at the level of the student body and faculty. It is extraordinary if one compares NCA with the Institute of Art and Design at the Punjab University, which was created almost at the same time as NCA. They are across the road, but if from NCA you enter the Institute at the Punjab University you are entering from one time zone to the other, because PU has much stronger presence of state control than NCA. There are multiple reasons for that, but the fact is that we have academic freedom in our classrooms; we question the state, military, and the religious orthodoxy. In PU they cannot do that due to the state control, ruling orthodoxy and so on, their appointments are from top to bottom, etc.'

Unfortunately, examples of institutions such as the NCA are rare and the major trend is for the government and political parties to influence universities. Such influences then have negative consequences for the institutions where disruptions to educational activities, including research, occur.

\section{Value of Research in Society}

The value of research too is linked with the overall societal progress, especially how research is valued by various stratum of population, which is dependent first on literacy level, and subsequently on linguistic accessibility of research findings to the wider public as mentioned earlier. 
There was a general feeling among some interviewees that the society as a whole is indifferent to the development of its most important institutions of education. On one hand, they relate it to the fact that the majority of the population is poor and not everyone has opportunity to get higher education and ultimately benefit from it, or pursue a career in research. This then deprives them from having access to research findings and appreciate its value. On the other hand, there are people who are affluent but they too do not necessarily invest in the long term educational career of their female offspring, or encourage them to do research (Muborakshoeva, 2013). The affluent Pakistanis are also not very supportive of universities and developing research there. A dean of an institute was particularly critical of the Pakistani philanthropists living abroad who do not value investing in public university:

'The Pakistani affluent [people] give a lot of donations in the name of God, in the name of khayrat, charity(...)in recent years there were millions of Arab rupees given by Pakistani expatriates from the Middle East, America, Canada, Europe, etc. Their thinking is that if they donate the money to the mosque they will get sawab, reward, from Allah... They do not take public service and institutions as a good cause (...)on certain occasions, back in England, I suggested why don't you want to contribute to Karachi University or Sindh University? But they have a very bad opinion about public universities. They are mostly university educated people (...) but their thinking is narrow(...)'

He further explained that in some mosques they regularly change the carpets or the pavements because of the abundance of money, yet the rich do not channel their funds to education and research. The affluent Pakistanis, especially those living in the Middle East and still holding Pakistani citizenship, do send their children to study at the top Pakistani universities and thus contribute to the universities' revenue (Muborakshoeva, 2013). Nevertheless they too, as some interviewees highlighted, do not necessarily invest in research enhancement in those universities.

A few interviewees blamed the universities in being detached from society and becoming 'ivory towers', which then results in the wider society being unaware of the type of research universities do, or having any awareness of the capability and potential of universities in resolving the larger issues of the society. Critics also point out other shortcomings such as scholars doing research mainly for the sake of promotion, issues of jealousy among faculty and lack of collaboration between them, universities not promoting research, 'tortuous processes of acquiring funds' for research, and the gulf between academia and industry (Zardari, 2014). It therefore seems that there is very little collaboration within universities. Furthermore, universities too are hardly proactive in creating links with industries or society as a whole.

\section{Discussion and Conclusion}

As it emerged from the analysis of the findings, universities in Pakistan face challenges such as funding and its effective use, academic freedom and value of research in society as some of the major impediments to enhancing research at the universities. It is therefore perhaps not easy for Pakistani universities to fulfil the HEC's plans to become research oriented institutions and transform the society to a knowledge-based one. It is claimed by HEC that 'the Medium Term Development Framework I (MTDF I) for 2005-2010 focused on the internal development of the institutions of higher learning as world class centres of learning and research' (MTDF II 2010-2015, p.4). Does this imply that Pakistani universities are now world-class? The characteristics of world-class or research university (by Altbach, 2007; Salmi, 2009) and challenges in research at universities we discussed here certainly makes it hard for us to call them as such.

It is praiseworthy that HEC wants universities 'to build economies, communities and leadership' and encourages them to reach out to the communities that host them and 'engage stakeholders to play their due role in the development of Pakistan' (MTDF II, 2010-15:10). Some universities in Pakistan, including some private ones, do have outreach activities and programs. Similarly research 
in various fields, including education and health are conducted by these universities, some of which are of a high quality.

As it also emerged, most research grants as well as most scholarship for PhDs abroad are given to sciences and IT, and not or social sciences/arts (see HEC's Annual Reports). HEC asserts that the lack of quality research in the social sciences and the arts is due to poor quality of research proposals, which in turn is thought to be a result of weakness within undergraduate education in these disciplines. However, the interviewees in this research thought it was due to the poor education at the primary and secondary levels. The brightest students and those from strong state and private schools study sciences, whilst the weaker ones end up being enrolled in humanities and social sciences.

Based on analysis of the findings here we propose the following recommendations for the government, the HEC, and the universities in Pakistan, which could also be enlightening for the universities in the developing world:

- Funding for universities and especially research should be increased and utilised effectively. The fact that the government funds the public universities, does not give it the right to interfere in all affairs of the universities.

- Conducive environment to produce quality research should be created at the universities. Quality research in all areas (on education, arts and sciences, health service, industries and technology, politics and social sciences) should be given equal importance and encouraged for publications in high rated journals.

- Academic freedom should be guaranteed and restrictions on academic freedom imposed by government and religio-political parties eradicated. Research conducted at universities should critically examine the economic, politico-ideological, socio-cultural, and religious issues of the society and propose solutions to such challenges. The government should utilise the research findings and involve academics as consultants in some of the decision making processes and policy making.

- The Ministry of Education (MoE) and HEC should collaborate with all institutions of higher education. For instance, madrasahs (Islamic schools) which provide higher and post-graduate education should be included in the research related policies for higher education. So far neither the MoE nor the HEC has worked out effective policies to engage with the teachers and students at these madrasahs. Lack of dialogue and disengagement with such institutions leaves the gap between religious and secular universities widely open and mutual mistrusts persevere.

- $\quad$ Responsible bodies for enhancing research at university and society as a whole should critically evaluate some terminologies used and in so doing must be careful when equating higher education with economic prosperity. Universities are think-tanks that propose solutions and nurture economic advancement, but they are not responsible for economic underachievement in a society. Universities should create links with the industries and build bridges with the societies that host them.

With regard to this last suggestion, it has been argued that historically, universities especially in the eighteenth to nineteenth century Europe, were not at the forefront of knowledge creation (Scott, 1984), rather universities benefited from the relatively well-developed economies and industries of the time. These developments forced universities to introduce grand reforms and adjust their curriculum to the demands of the emerging economies (Muborakshoeva, 2013). Thus universities grabbed this 'imposed' responsibility on them with both hands. Today they have become knowledge producers, which means that in the developed world societies and their industries and economy are dependent on universities. Unless investment in higher education grows extensively Pakistani universities will hardly become world-class universities.

As far as funding is concerned, it is getting harder for universities the world over to justify their research activities to society and getting fund from public budget. Research universities globally are 
publicly funded with the exception of a few private universities and this is largely due to the fact that universities were seen as a public good (Altbach, 2007). With the neoliberal economic approach since 1980s it was highlighted that because university education brings enormous advantages to the individual then it is a private good and individuals should contribute to the cost of higher education. Student tuition fee alone though cannot sustain research universities (Ibid, p.12).

Therefore perhaps these two additional measures should be taken into account by universities in Pakistan and developing countries. Firstly, consider differentiation of funding for universities as Altbach (2007) suggests. He states that "research universities generally constitute part of a differentiated academic system - an arrangement of post-secondary institutions with varied roles in society and different funding patterns" (p.5). He then gives the example of Germany which considers all its universities as research universities and as a result struggles in funding all of them. Countries such as USA and UK that do have the differentiated funding system for higher education, are very successful in developing their research universities. Secondly, state and universities should play their respective roles in transforming universities from ordinary to research or world-class universities. As suggested by Salmi (2009) the universities should be pro-active in working with organisations such as the World Bank for obtaining technical and financial support. State should support universities in these initiatives and explore creative ways of organising research at universities and increase funding for research at universities if a knowledge-based society is desirable.

Consequently, it is hoped that the findings of this research are useful for the government, HEC and university management and faculty in Pakistan and are informative for other universities in the developing countries. Universities in the developing countries could benefit from learning about successful reform initiatives by HEC and reflect on the persistent challenges universities face and how to overcome them.

\section{Notes}

I am grateful to all the interviewees in Pakistan for their participation in and contribution to this study.

\section{References}

Akhtar, N. (1977). A History of the University of Karachi. From Inception to Silver Jubelee (1951-76 A.D.). Karachi: University of Karachi Press.

Ashwin, P. (2012). How often are theories developed through empirical research into higher education? Studies in Higher Education, 37 (8), 941-955.

Altbach, P. G. (2007). Empires of Knowledge and Development. In P.G Altbach. and J. Balan (Eds.) World Class Wordwide: Transforming Research Universities in Asia and Latin America. Maryland: John Hopkins University Press.

Altbach, P.G. (2013). Advancing the national and global knowledge economy: the role of research universities in developing countries, Studies in Higher Education, 38 (3), 316-330.

Altbach, P. G. , Bozeman, L. A. , Janashia, N. and Rumbley, L. E. (2006). Higher Education A Worldwide Inventory of Centers and Programs. Rotterdam: Sense Publishers.

Altbach, P.G. (2013). Advancing the national and global knowledge economy: the role of research universities in developing countries, Studies in Higher Education, 38 (3), 316-330.

Birdsall, N. (1996). Public Spending on Higher Education in Developing Countries: Too Much or Too Little? Economics of Education Review, 15(4), 407-19.

Bastalich, W. (2010). Knowledge economy and research innovation. Studies in Higher Education, 35(7), 845-857.

Government of Pakistan (2002). Challenges and Opportunities: The Task Force on the Improvement of Higher Education in Pakistan. Pakistan: Government Publications.

Glazer, B. G. and Strauss, A. L. (1967). The Discovery of Grounded Theory: strategies for qualitative research. New York: Aldine de Gruyter. 
Higher Education Commission. (2011a). HEC After Absconders. Available at: http://www.dawn.com/ news/677669/ [Accessed 9 February 2015].

Higher Education Commission (2011b). Annual Report (2010-11). Available at: http://www.hec.gov. pk [Accessed 25 January 2014].

Higher Education Commission (2012). Annual Report (2011-12). Available at: http://www.hec.gov. pk [Accessed 25 January 2014].

Higher Education Commission (2013). Annual Report (2012-13). Available at: http://www.hec.gov. pk [Accessed 24 January 2014].

Higher Education Commission. (2014). The visit of the scholars from CERN. Available at: http://www. hec.gov.pk/MediaPublication/NewsViews [Accessed on 24 January 2014].

Hoodbhoy, P. (2010). From Boom to Bust. Dawn Newspaper, 25 September, n.p.

Isani, U.A. and Virk, M.L. (2005). Higher Education in Pakistan: a historical and futuristic perspectives. Islamabad: National Book Foundation.

Junaidi, I. (2014). Education budget decreased despite promises. Available at: http://www.dawn. com/news/1110706/ [Accessed 24 January 2014].

Jung, J. and Horta, H. (2013). Higher Education Research in Asia: a Publication and Co-Publication Analysis. Higher Education Quarterly, 67 (4), 398-419.

Kapur, D and Crowley, M. (2008). Beyond the ABCs: Higher Education and Developing Countries Working Paper Number 139. Centre for Global Development. Available at: http://www.cgdev. org/files/15310_file_HigherEd.pdf [Accessed 24 January 2014].

Laghari, J. (2010). The Reforms in Higher Education. Available at: http://www.dawn.com/ news/872461/reforms-in-higher-education [Accessed 24 January 2014].

Mathur, L.P. (1968). University of the Punjab, Lahore: Its Origins and Objects. Punjab Past and Present, 2 (1), 28-61.

Muborakshoeva, M. (2013). Islam and Higher Education: Concepts, Challenges and Opportunities. Abingdon: Routledge.

Medium Term Development Framework II (MTDF II) (2010-15). Available at: http://www.hec.gov. pk. [Accessed 25 January 2014].

Paracha, F. N. (2014). Student politics in Pakistan: A celebration, lament \& history. Available at: http:// www.dawn.com/news/1116782 [Accessed 24 January 2014].

Robson, C. (2012). Real World Research (2nd ed.). Oxford: Blackwell

Salmi, J. (2009). The Challenges of Establishing World-Class Universities. Washington DC: World Bank. Scott, P. (1984). The Crisis of the University. London: Biddles Ltd.

Singh, N. (1993). Leitner in Lahore: Life and Works. The Punjab Past and Present, 27 (53), 119-223.

SJR (2015). Country rankings. Available at: http://www.scimagojr.com/countryrank.php. [Accessed 24 January 2015].

Strauss, A. L. and Corbin, J. (1998). Basics of Qualitative research: Techniques and Producers for Developing Grounded Theory (2nd ed.). California: Sage Publication.

Symaco, L.P. (2012). Higher Education in the Philippines and Malaysia: The learning region in the age of knowledge-based societies. Journal of International and Comparative Education, 1(1), 40-51.

Tilak, J.B.G. (2002). Knowledge society, education and aid. Compare, 32 (3), 297-310.

UNESCO. (1998). Higher Education in the Twenty-first Century: Vision and Action. Working Document. World Conference on Higher Education, Paris, 5-9 October.

World Bank. (2000). Higher Education in Developing Countries Perils and Promise. The Task force on Higher Education and Society. Washington DC: World Bank.

World Bank. (2002). Constructing Knowledge Societies: New Challenges for tertiary education. Washington D.C: World Bank.

Zardari, S. (2014). Beyond the sorry state of research at our universities and how to fix it. Available at: http://www.dawn.com/news/1141829 [Accessed 9 February 2015]. 